\title{
Miocardiopatía dilatada idiopática asociada a fibrosis intramiocárdica
}

\section{Idiopathic dilated cardiomyopathy associated with intramyocardial fibrosis}

\author{
Francisco Sánchez Lezama, ${ }^{*}$ Jorge Ignacio Magaña Reyes, ${ }^{\ddagger}$ Carlos Harrison Gómez ${ }^{\S}$
}

Hombre de 78 años, con sensación de fatiga y disnea de medianos esfuerzos durante los últimos seis meses; por esta razón, su estilo de vida es sedentario. Encontramos a la exploración los siguientes datos de relevancia: FC de 70 latidos/min; TA 90/60; FR $18 \mathrm{r} / \mathrm{min}$; sin presencia de hepatomegalia ni edema de miembros inferiores, por lo

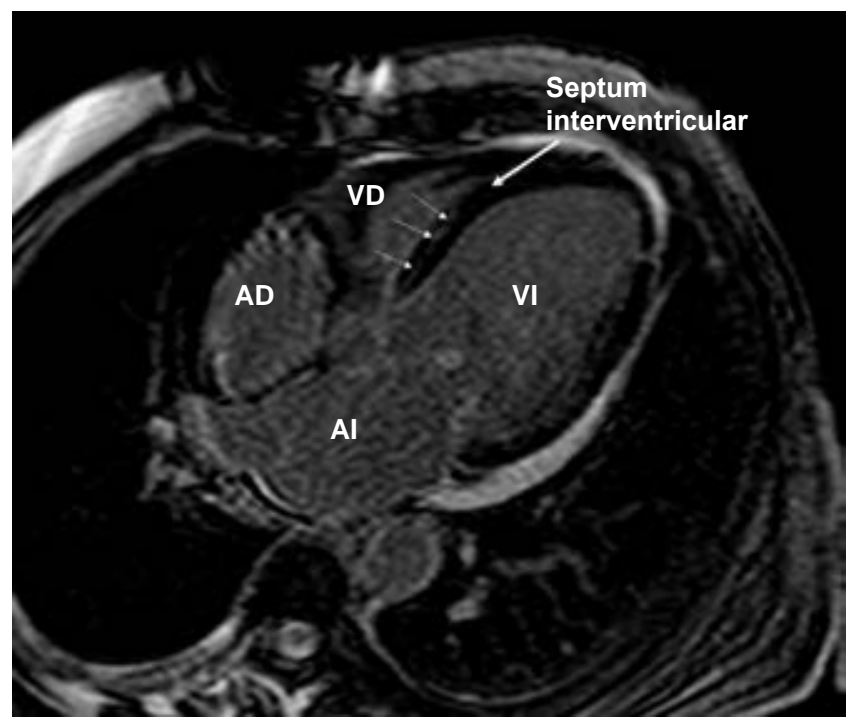

Figura 1.

\footnotetext{
* Cardiólogo. Ecocardiografista.

‡ Departamento de Imagenología.

§ Cardiólogo.
}

Hospital Ángeles León, León, Guanajuato. México

Correspondencia:

Dr. Francisco Sánchez Lezama

Correo electrónico:

sanchezlezama@angelesleon.com

Aceptado: 30-07-2019.

www.medigraphic.com/actamedica demás se encontró asintomático. En clase funcional, se encontró en II-III de NYHA.

Se le indicó un estudio de imagenología con resonancia magnética, en el cual se halló una miocardiopatía dilatada con fracción de eyección del ventrículo izquierdo de $18 \%$. Las imágenes de secuencias mostraron una inversión y recuperación para reforzamiento tardío en cuatro cámaras para visualizar ventrículos y aurículas (Figura 1) y un eje corto para visualizar ambos ventrículos (Figura 2), lo que permitió observar la hiperintensidad intramiocárdica lineal septal (flechas de figuras) en el tercio basal, así como en los sitios de unión VD/VI, los cuales correspondieron a fibrosis, empobreciendo el pronóstico.

Es por lo anterior que se inició tratamiento con $\beta$-bloqueador a dosis bajas, espironolactona e inhibidor de la enzima convertidora de angiotensina; posteriormente, en tres semanas, pasó a clase funcional I de NYHA. Se planteó al paciente y a sus familiares el implante de desfibrilador $y$, una vez aceptado, se derivó a Cardiología intervencionista para ello.

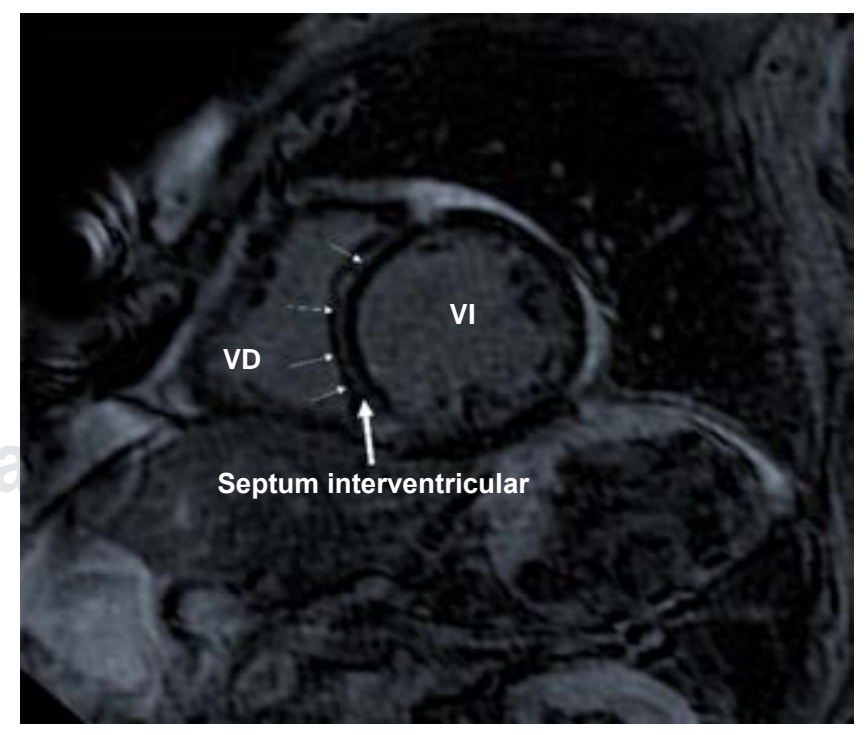

Figura 2. 
El Video 1 muestra la secuencia de cine en eco de gradiente, en cuatro cámaras; revela una disfunción sistólica severa del ventrículo izquierdo, pérdida del engrosamiento sistólico e hipocinesia difusa. Hay también disincronía. El movimiento de la pared libre del ventrículo derecho es normal; hay mínima insuficiencia tricuspídea. www.medigraphic.com/videos/actmed/am201y1

El Video 2 muestra la secuencia de cine en eje corto, con disincronía y acinesia de las paredes septal e inferior, así como hipocinesia de las paredes anterior, anterolateral e inferolateral, observándose pobre engrosamiento sistólico. www.medigraphic.com/videos/actmed/am201y2

En los pacientes con miocardiopatía dilatada, clínicamente, la fracción de eyección está disminuida y existe fallo de bomba con insuficiencia cardiaca progresiva. El $50 \%$ de los pacientes fallecen por muerte súbita debido a arritmias, y el resto, por insuficiencia cardiaca intratable.

Histológicamente, la miocardiopatía dilatada se caracteriza por miocitos con hipertrofia, con un diámetro transversal menor al normal, degeneración con núcleos irregulares, hiperplasia de mitocondrias pequeñas, focos de muerte celular y fibrosis (ya sea focal, intersticial, pericelular o perivascular), que se manifiesta por citoplasmas vacuolados. Se ha descrito un marcado aumento del colágeno tipo I y III en el espacio intersticial, con aumento de la relación colágeno tipo I/tipo III. La concentración de colágeno es el doble, y la cantidad de colágeno es el cuádruple en los casos de miocardiopatía dilatada en la pared ventricular más que en los corazones normales.

Mediante el análisis de imagen, la fibrosis es el dato más característico de la enfermedad para su diagnóstico. Cuando la fibrosis representa menos del $10 \%$ la fracción de eyección es alta y la clase funcional es I, pero si la fibrosis es mayor del $10 \%$ la fracción de eyección disminuye y los enfermos se encuentran en clase funcional III. Por ello, se concluye que la extensión de la fibrosis es un buen índice pronóstico en la miocardiopatía dilatada.

El trasplante cardiaco ofrece actualmente una supervivencia de $66 \%$ a los cinco años; sin embargo, se encuentra limitado por falta de donantes. Asimismo, el implante de desfibrilador ofrece mejor supervivencia que los fármacos. 